\title{
330MW 机组深度调峰试验分析
}

\section{Analysis of Depth Peak Shaving Test for 330MW Unit \\ 张建伟 何立建 \\ Jianwei Zhang Lijian He}

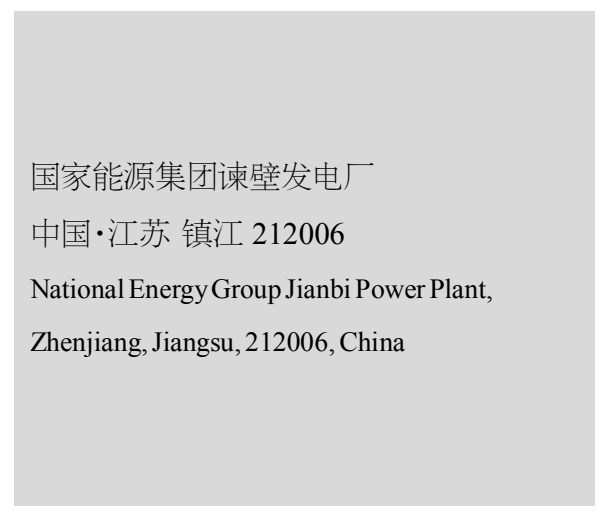

【摘要】主要围绕如何提高火电机组的调峰能力展开论述。通过低负荷试验、燃烧优化, 对 330MW 火电机组的调峰能力进行试验, 同时对深度调峰下机组的安全性进行分析。

【Abstract】This paper mainly discusses how to improve the peak regulation capacity of thermal power units. Through low load test and combustion optimization, the peak shaving capacity of $330 \mathrm{MW}$ thermal power unit is tested, and the safety of the unit under deep peak load regulation is analyzed.

【关键词】火电机组; 深度调峰; 磨煤机; 安全运行

【Keywords】thermal power unit; depth peak shaving; coal mill; safe operation

【DOI】10.36012/peti.v2i2.1736

\section{1 引言}

近几年随着国家大力发展新能源, 光伏和风电装机量呈 井喷式高速增长。国家近两年已密集出台了一系列政策和配 套文件以加强火电机组监管, 确保新能源优先上网。同时, 华 东部分地区居民用电递增速度甚至已经超过了工业用电, 造 成电网负荷峰谷差越来越大, 调峰已经是电网必须面对的重 要问题。江苏电网为解决调差缺口对燃煤发电机组的调峰能 力提出了最新要求: 所有 $300 \mathrm{MW}$ 及以上燃煤发电机组调峰 能力至少达到机组 $35 \%$ 额定出力的要求 ${ }^{[1]}$ 。

\section{2 机组概况}

某电厂为 330MW 亚临界一次中间再热燃煤凝汽式机 组,亚临界控制循环汽包锅炉。该锅炉为一次中间再热、单炉 膛 $\Pi$ 型, 露天布置、四角切圆燃烧、高强度螺栓全钢架悬吊结 构、固态排渣。配备五台正压直吹式制粉系统, 从低到高对应 $A 、 B 、 C 、 D 、 E$ 五层低氮燃烧器。脱硝系统采用选择性催化剂还 原法 (SCR)。锅炉额定蒸发量为 $1036 \mathrm{t} / \mathrm{h}$, 过热器额定压力为 $17.5 \mathrm{MPa}$, 过热蒸汽温度为 $541^{\circ} \mathrm{C}$, 再热蒸汽温度为 $563^{\circ} \mathrm{C}$ 。汽 轮机为上海汽轮机发电有限公司生产的单轴、一次中间再热、 两缸两排汽凝器式汽轮机。

\section{3 深度调峰试验}

\section{1 配煤方式}

机组深度调峰前, 我们对制粉系统的配煤方式进行了调 整: $\mathrm{BC}$ 仓为高热值的神混煤种, 热值为 $21.36 \mathrm{MJ} / \mathrm{kg}, \mathrm{AD}$ 仓为 低热值的印尼煤种, 热值为 $13.81 \mathrm{MJ} / \mathrm{kg}$ 。机组深度调峰试验开
始, 负荷由 $180 \mathrm{MW}$ 降至150MW, 按正常的降负荷速度进行操 作, 逐步停运了 A 制粉系统, 保留了 BCD 制粉系统运行。降 负荷过程中,二次风配风方式调整为微束腰配风。提高磨煤机 旋转分离器转速后将机组变负荷速率调整为 $0.7 \%$, 继续降低 机组负荷至 $115 \mathrm{MW}$ 。加仓煤种参数见表 1 , 机组负荷与煤量 对应关系见图 1 。

表 1 加仓煤种参数

\begin{tabular}{c|c|c|c|c|c|c}
\hline \multirow{2}{*}{ 煤种 } & \multicolumn{7}{|c}{ 数据 } \\
\cline { 2 - 7 } & 全水 $/ \%$ & $\begin{array}{c}\text { 收到 } \\
\text { 基灰分 } 1 \%\end{array}$ & $\begin{array}{c}\text { 挥发 } \\
\text { 分 } / \%\end{array}$ & $\begin{array}{c}\text { 收到基发热 } \\
\text { 量 } /(\mathrm{MJ} / \mathrm{kg})\end{array}$ & $\begin{array}{c}\text { 干燥 } \\
\text { 基硫/\% }\end{array}$ & 灰熔点 \\
\hline 神混 & 19.4 & 9.83 & 27.53 & 21.5 & 0.38 & 低 \\
\hline 印尼 & 41.1 & 2.98 & 29.30 & 13.81 & 0.15 & 低 \\
\hline
\end{tabular}

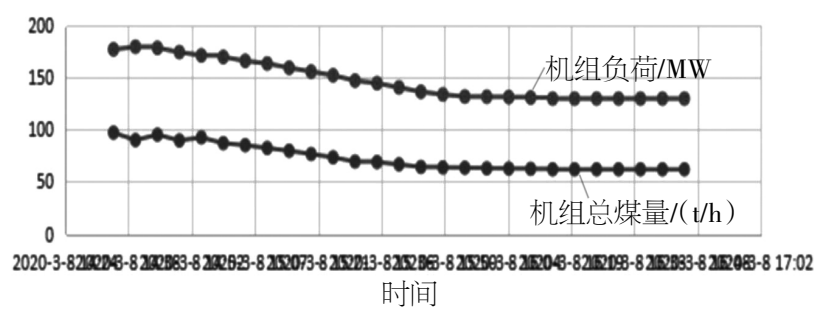

图 1 机组负荷与煤量对应关系

\section{2 试验过程及数据}

深度调峰试验期间，锅炉各项参数指标均在正常范围内

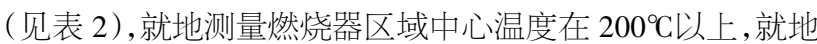
检查各燃烧器着火为金黄色, 燃烧比较稳定。

\section{4 机组深度调峰时采取的措施}

机组深度调峰时, 由于锅炉热负荷低, 可能引起燃烧不稳 或者燃烧恶化甚至炉膛灭火的情况，深度调峰时机组各主要 运行参数远低于设计值, 任何异常参数都可能对机组安全运 
表 2 深度调峰参数

\begin{tabular}{c|c}
\hline 项目 & 数据 \\
\hline 负荷 $/ \mathrm{MW}$ & 115 \\
\hline 主汽压 $/ \mathrm{MPa}$ & 8.60 \\
\hline 主蒸汽温度 $/{ }^{\circ} \mathrm{C}$ & 539 \\
\hline 再热蒸汽温度 $/{ }^{\circ} \mathrm{C}$ & 542 \\
\hline 再热汽压 $/ \mathrm{MPa}$ & 1.15 \\
\hline 给水流量 $/(\mathrm{t} / \mathrm{h})$ & 375 \\
\hline 主蒸汽流量 $/(\mathrm{t} / \mathrm{h})$ & 375 \\
\hline 总煤量 $/(\mathrm{t} / \mathrm{h})$ & 60 \\
\hline 排烟温度 $/{ }^{\circ} \mathrm{C}$ & 120 \\
\hline $\mathrm{SCR}$ 人口烟温 $/{ }^{\circ} \mathrm{C}$ & 298 \\
\hline 烟图出口 $\mathrm{NO}_{x}$ 浓度 $/\left(\mathrm{mg} / \mathrm{m}^{3}\right)$ & 25 \\
\hline
\end{tabular}

行造成不利的影响。因此, 在机组深度调峰的过程中, 我们采 取了下面几方面的运行措施:

(1)在低负荷变工况时, 燃烧调整应缓慢谨慎进行, 调整时 需特别注意火检变化、炉膛负压、水位、汽压、汽温等参数变 化。在降负荷过程中, 人为降负荷速率至 $0.5 \%$ 0.7\%, 如果出 现参数较大幅度波动, 立即停止降负荷, 稳定参数运行。

(2)磨煤机的投运方式对锅炉低负荷工况影响很大, 集中燃 烧器运行相对于分散燃烧运行稳定性更强。在进行深度调峰时 选择投运相邻的磨煤机运行, 减少投运台数, 提高一次风管煤 粉浓度, 使炉膛热负荷更集中, 加强低负荷锅炉稳燃能力。

(3)深度调峰时, 我们保留了 $\mathrm{B} 、 \mathrm{C} 、 \mathrm{D}$ 磨煤机运行, 其中, B、 C 磨煤机为神混高热值煤种, D 磨煤机为低热值印尼煤。其中, $B 、 C$ 磨煤机带基本煤量 $>20 t / h$, 且磨煤机旋转分离器转速 $>650 \mathrm{r} / \mathrm{min}$, 提高制粉系统煤粉细度, 保证锅炉燃烧着火稳定。

(4)深度调峰期间合理配风, 减少上层 SOFA 各风门挡板 开度, 开大各燃烧器对应二次风门, 采用微束腰配风方式, 减 少燃烧器附近高温腐蚀的形成。同时适当降低炉膛一次风量 占比, 降低各台磨煤机一次风速, 保证各燃烧器对应二次风的 刚性,防止火焰偏斜。

(5)汽包水位也是深度调峰重点监视调整的指标。深度调 峰减负荷期间, 要保证汽洜小机转速不能低于 3300r/min, 否 则会造成汽包水位洜控退出, 增加系统的扰动。我们采取的方 法是: 在接到省调深度调峰的指令时, 将一台汽原的起源疏水 暖管, 当负荷降至 $135 \mathrm{MW}$ 左右时, 将一台汽百汽源切至辅汽 供给, 防止小机调门开度较大、无调节裕度的情况发生。

(6)环保参数烟图出口 $\mathrm{NO}_{x}$ 数值任何时候也不能超标运行。 在锅炉深度调峰期间, 需保障脱硝 SCR 人口的烟温不能低于 $300^{\circ} \mathrm{C}$, 否则脱硝催化剂活性和寿命将受到极大的影响。在深度 调峰期间,随着负荷的降低,SCR 人口烟气温度也同步降低。当 $\mathrm{SCR}$ 人口烟温 $<315^{\circ} \mathrm{C}$ 时, 应先维持负荷, 通过投用汽机 $0^{\#}$ 高 加, 提高省煤器给水温度, 减少省煤器吸热量, 提高 SCR 进口 烟温度 $\geqslant 305^{\circ} \mathrm{C}$ 后, 再继续降负荷保证脱硝系统的正常运行。

(7)深度调峰期间由于烟气流速降低, 受热面特别是空气
预热器部位容易积灰, 要保持空预器连续吹灰, 防止燃烧不充 分造成烟道尾部再燃烧。

(8)汽轮机运行方面, 在深度调峰的过程中, 汽轮机轴封自 密封变差, 需特别对轴封压力的监视调整。凝泵变频调整时, 提前将凝洜频率降至最小频率, 通过除水调整器调节, 以确保 除氧器水位正常。另外, 还需特别加强对主机振动、差胀及上、 下缸温差的监测。

(9)机组深度调峰前做好油枪试投工作, 保证各层油枪可 靠备用,做好锅炉燃烧不稳随时可以投油稳燃。

\section{5 深度调峰对机组的影响}

\section{1 低负荷下锅炉安全}

机组深度调峰过程中, 制约安全的最大因素就是锅炉燃烧 不稳定。锅炉燃烧工况不稳定时, 会出现火检信号晃动现象, 此 时容易发生灭火放炮事故。主要原因有以下几个方面: 一是然 煤加仓煤质变化幅度较大; 二是制粉系统燃烧调整不到位, 煤 粉细度、一次风粉混合物温度、磨组运行方式等不合理。

\section{2 低负荷下汽动给水洜安全}

深度调峰时, 锅炉所需给水流量较小, 汽原出力变化较大 且不稳定, 容易造成给水流量波动。主要是以下原因造成:一 是小汽轮机进汽压力偏低, 小汽轮机低压进汽调门开度大, 裕 度不够, 影响汽洜出力; 二是汽动给水泵在循环门开启时若遇 到卡涩情况, 汽动给水泵入口流量低于最小安全允许流量, 直 接威胁汽洜安全运行。深度调峰时必须保证汽原的安全运行。

\section{3 深度调峰工况下脱硝系统安全运行}

在锅炉低负荷运行过程中, 存在运行氧量偏大的情况, 使 得 SCR 人口 $\mathrm{NO}_{x}$ 数值偏高, 造成喷氨调门开度大, 喷氨流量 增大, 导致氨逃逸率升高; 在较低烟气温度下, 烟气中的 $\mathrm{SO}_{3}$ 与 $\mathrm{NH}_{3}$ 结合成 $\mathrm{NH}_{4} \mathrm{HSO}_{4}$, 极易造成空预器腐蚀、积灰、堵塞。

\section{4 深度调峰时加热器运行安全}

减负荷较快时, 加热器会产生虚假水位, 如果正常疏水门、 危急疏水门调整不及时, 容易导致加热器解列。加热器解列后, 会造成给水温度降低, 导致脱硝入口烟温下降。同时, 脱硝进 口烟气温度过低会造成脱硝系统跳闸, 影响机组的环保安全。

\section{6 结语}

在电网公司现行的调峰政策下, 机组调峰幅度越大, 电厂 获得的收益越大。在机组深度调峰过程中, 机组的实际运行工 况较设计工况偏差大, 机组的安全运行受到威胁, 如需继续下 调机组的深度调峰能力, 还需开展相关试验, 确保机组安全。

\section{参考文献}

[1]国家发展和改革委员会,国家能源局.电力发展“十三五”规划 (2016-2020 年) [Z]. 